\title{
Sequential Changes in Plasma Fibronectin in Patients with Subarachnoid Hemorrhage
}

\author{
Shiro KASHIWAGI, Yujiro SHIRoYAMA, Tetsuaki Iwamoto, \\ Tetsuo YAMASHITA and Haruhide ITO
}

Department of Neurosurgery, Yamaguchi University School of Medicine, Ube, Yamaguchi

\begin{abstract}
Sequential changes in plasma fibronectin level in 17 patients with subarachnoid hemorrhage (SAH), with 16 due to ruptured cerebral aneurysms, were compared for patients with good and poor outcomes, and patients with and without vasospasm. Plasma fibronectin concentrations were measured by an immune diffusion method. The clinical outcome was evaluated 3 months after SAH according to the Glasgow Outcome Scale. Plasma fibronectin concentrations were significantly lower on days $3(\mathrm{p}<0.02)$ and $9(\mathrm{p}<0.05)$ after ictus in patients with poor outcomes (moderately disabled or worse) than in those with good outcomes (good recovery). Patients with vasospasm had lower fibronectin concentrations during the 4 weeks after ictus. Decreased levels of plasma fibronectin were correlated with poor outcomes, most related to vasospasm. Plasma fibronectin levels reflect the overall severity in patients with SAH and are a useful marker for prediction of the final clinical outcome.
\end{abstract}

Key words: fibronectin, outcome, subarachnoid hemorrhage, vasospasm

\section{Introduction}

Cerebral vasospasm and rebleeding are two major causes of death and disability after subarachnoid hemorrhage (SAH) due to a ruptured cerebral aneurysm. Once the aneurysm has been clipped successfully, the severity of the vasospasm becomes one of the main factors determining the outcome. However, no single hematological marker can predict the occurrence of vasospasm.

Fibronectin is a high molecular weight glycoprotein found in a soluble form in the blood and in an insoluble form in connective tissues, and associated with basement membranes. ${ }^{8.14,28)}$ It interacts with collagen, ${ }^{1,11)}$ fibrin, ${ }^{19,25)}$ and other components of hemostatic and fibrinolytic systems. . $^{40,13,15,18)}$ Since endothelial damage, ${ }^{6,12)}$ coagulopathy, ${ }^{2,5,26,27)}$ and complement-activating immune complexes ${ }^{17)}$ are involved in the process underlying vasospasm, the plasma fibronectin concentration may reflect the severity of the disease and be correlated with the final outcome.

This study measured the sequential changes in

Received June 23, 1992; Accepted September 22, 1992 plasma fibronectin level in patients with SAH, and investigated correlation with the final clinical outcome and occurrence of symptomatic cerebral vasospasm.

\section{Materials and Methods}

Table 1 summarizes the clinical data for the 17 patients in this study. There were eight females and nine males, ranging in age from 43 to 78 years (mean, $62.2 \mathrm{yrs}$ ). Sixteen patients presented with SAH due to ruptured cerebral aneurysms and one with SAH of unknown origin. Clinical status on admission was determined by the Hunt and Kosnik scale, ${ }^{7}$ and the severity of SAH on admission by the Fisher computed tomographic (CT) scale. ${ }^{3)}$ Fifteen patients were operated on to clip ruptured aneurysms. Symptomatic vasospasm was defined clinically as delayed neurological deterioration including disturbed consciousness and a focal neurological deficit with CT evidence of local ischemia. Neurological deterioration due to hydrocephalus or rebleeding was excluded by $\mathrm{CT}$. The outcome was assessed 3 months after ictus according to the Glasgow Outcome Scale (GOS). ${ }^{\text {9) }}$

Blood samples were collected on days $1,3,5,7,9$, 
Table 1 Summary of the 17 patients in this study

\begin{tabular}{|c|c|c|c|c|c|c|c|}
\hline Case No. & Age/Sex & $\begin{array}{l}\text { Location of } \\
\text { aneurysm }\end{array}$ & $\begin{array}{l}\text { Clinical } \\
\text { grade }^{*}\end{array}$ & $\begin{array}{c}\text { Severity of } \\
\text { SAH }^{* *}\end{array}$ & $\begin{array}{l}\text { Timing of } \\
\text { operation }\end{array}$ & Vasospasm & Outcome ${ }^{* * *}$ \\
\hline 1 & $57 / \mathrm{F}$ & lt MCA & I & 2 & $\mathrm{EO}$ & - & GR \\
\hline 2 & $63 / \mathrm{F}$ & rt MCA & II & 3 & EO & - & GR \\
\hline 3 & $63 / F$ & none & II & 3 & not done & - & GR \\
\hline 4 & $75 / \mathrm{F}$ & It IC-PComA & II & 3 & EO & + & GR \\
\hline 5 & $50 / \mathrm{M}$ & AComA & II & 2 & EO & - & GR \\
\hline 6 & $43 / \mathrm{M}$ & AComA & II & 3 & DO & - & MD \\
\hline 7 & $73 / \mathrm{M}$ & AComA & II & 2 & DO & + & MD \\
\hline 8 & $59 / \mathrm{M}$ & $\mathrm{rt} \mathrm{MCA}$ & II & 3 & EO & + & MD \\
\hline 9 & $58 / \mathrm{F}$ & It PCA & III & 3 & DO & + & GR \\
\hline 10 & $53 / \mathrm{M}$ & AComA & III & 3 & $\mathrm{EO}$ & + & GR \\
\hline 11 & $63 / \mathrm{M}$ & rt IC-AChA & III & 3 & $\mathrm{EO}$ & + & MD \\
\hline 12 & $57 / \mathrm{M}$ & rt PCA & III & 3 & DO & - & MD \\
\hline 13 & $63 / \mathrm{F}$ & It MCA & III & 3 & EO & - & MD \\
\hline 14 & $62 / \mathrm{F}$ & AComA & III & 4 & EO & + & MD \\
\hline 15 & $78 / \mathrm{M}$ & rt MCA & III & 3 & DO & + & $\mathrm{SD}$ \\
\hline 16 & $68 / \mathrm{M}$ & AComA & III & 4 & EO & + & D \\
\hline 17 & $73 / \mathrm{F}$ & unverified & III & 3 & not done & + & $\mathrm{D}$ \\
\hline
\end{tabular}

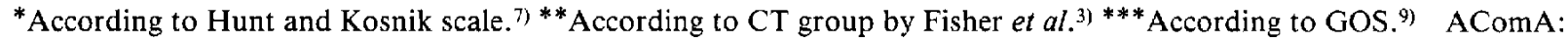
anterior communicating artery, D: died, DO: delayed operation over 2 weeks, EO: early operation within 3 days of ictus, GR: good recovery, IC-AChA: internal carotid-anterior choroidal arteries, IC-PComA: internal carotid-posterior communicating arteries, MCA: middle cerebral artery, MD: moderately disabled, PCA: posterior cerebral artery, SD: severely disabled.

$11,14,21$, and 28. Plasma was separated and stored at $-20^{\circ} \mathrm{C}$ until analysis. The plasma fibronectin concentration was measured by an immune diffusion method, using LC Paltigen fibronectin ${ }^{\circledR}$ (Behringwerke AG, Frankfurt, Germany). Platelet counts, fibrinogen, fibrinogen degradation product (FDP), D-dimer, and plasmin-inhibition complex (PIC) were also measured.

The results are expressed as means $\pm \mathrm{SE}$, and groups compared using Student's t-test.

\section{Results}

The clinical outcome was good (good recovery) in seven patients and poor (moderately disabled, severely disabled, and died) in 10 (Table 1). Figure 1 shows the sequential changes in fibronectin concentrations in patients with good and poor outcomes. The poor outcome group had lower fibronectin concentrations during the 1 st week, with statistically significant differences on days $3(\mathrm{p}<0.02)$ and 9 $(\mathrm{p}<0.05)$.

Symptomatic vasospasm occurred in 10 patients (Table 1). Figure 2 shows sequential changes in fibronectin concentrations in patients with and without vasospasm. Patients with vasospasm had lower concentrations throughout the 4-week monitor-

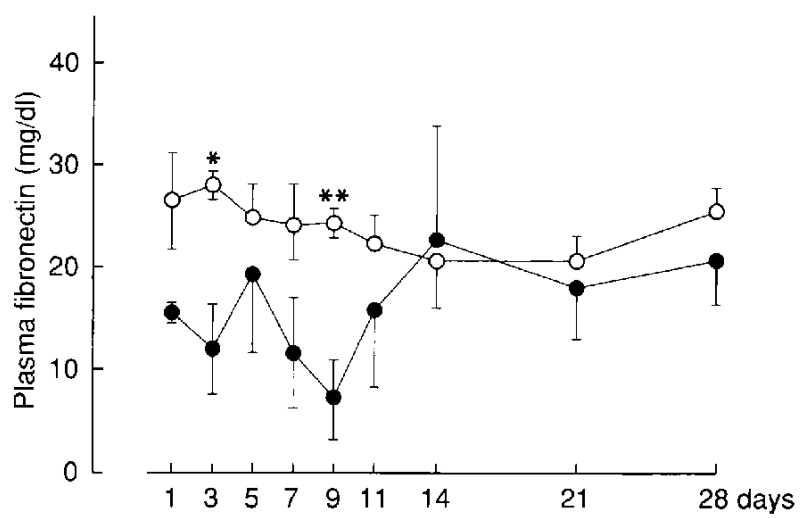

Fig. 1 Sequential changes in plasma fibronectin concentrations in patients with good (open circles) and poor outcomes (closed circles). The poor outcome group had lower fibronectin concentrations during the 1st week, the differences being statistically significant on days 3 and 9 $\left({ }^{*} \mathrm{p}<0.02,{ }^{* *} \mathrm{p}<0.05\right)$.

ing period, especially after day 5 , although the differences were not statistically significant.

Statistically significant $(p<0.05)$ decreases in platelet count and increases in D-dimer and PIC values were observed in patients with vasospasm, 


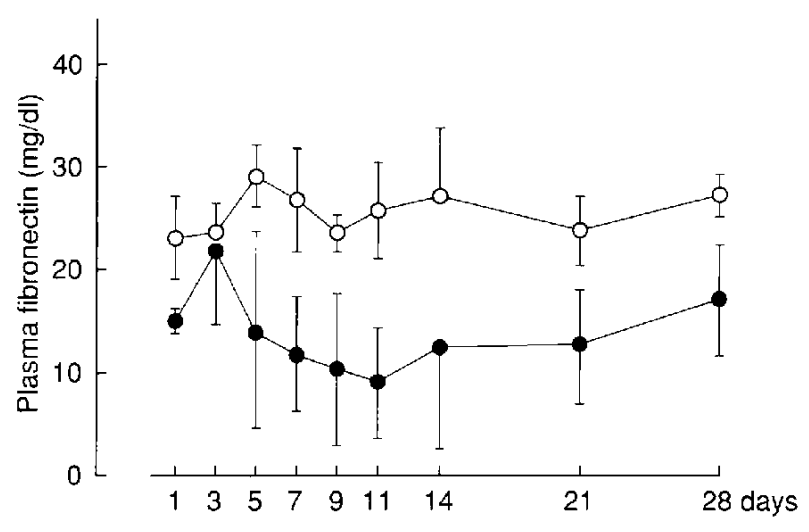

Fig. 2 Sequential changes in plasma fibronectin concentrations in patients with (closed circles) and without vasospasm (open circles). The patients with vasospasm had lower concentrations during the 4 weeks after ictus, especially after day 5. The differences were not statistically significant.

compared to those without vasospasm.

\section{Discussion}

Plasma fibronectin levels decrease in patients following major surgery or major trauma, and in severely ill patients with evidence of disseminated intravascular coagulation. ${ }^{21-23)}$ The concentration of plasma fibronectin required for normal function is unknown, but patients with less than $50 \%$ of the normal concentration had a higher mortality than those with normal concentrations. ${ }^{16,23)}$ Non-surviving trauma patients demonstrate a persistent depletion of plasma fibronectin, while survivors with equally severe injuries show early restoration of the normal level after trauma. ${ }^{23)}$

Since rebleeding caused clinical deterioration in none of our patients, cerebral vasospasms were regarded as the major cause of mortality and disability. The plasma fibronectin concentrations were lower in patients with symptomatic vasospasm than in those without. A condition similar to disseminated intravascular coagulation occurs in patients with vasospasm due to endothelial damage in the cerebral arteries. ${ }^{2,5,26,27)}$ The hematological markers in our patients, such as platelet counts, FDP, D-dimer, and PIC values, suggested that intravascular coagulation was associated with the decreased plasma fibronectin levels. Therefore, the depletion of plasma fibronectin resulted from deposition of fibronectin in thrombi, binding to areas of tissue injury due to its high affinity for damaged tissue, and utilization as a nonspecific opsonin in the reticuloendothelial disposal of circulating fibrin complexes. ${ }^{20,24)}$ Persistent depletion of plasma fibronectin may induce detachment of vascular endothelial cells because the plasma fibronectin pool may contribute to the cell surface fibronectin pool, which is important in the adhesion of endothelial cells to the subendothelium. This could aggravate the process of vasospasm and may also impair the healing of damaged tissue.

Our study indicated that a decreased level of plasma fibronectin during the 1st week after $\mathrm{SAH}$ was related to a poor outcome at 3 months, and that patients with symptomatic vasospasm tended to have lower levels of plasma fibronectin during the 4 weeks after SAH. These results suggested that the plasma fibronectin concentration reflects the overall severity in patients with SAH, and is a useful prognostic marker for the final outcome.

\section{References}

1) Engvall E, Ruoslahti E, Miller EJ: Affinity of fibronectin to collagens of different genetic types and to fibrinogen. J Exp Med 147: 1584-1595, 1978

2) Ettinger MG: Coagulation abnormalities in subarachnoid hemorrhage. Stroke 1: 139-142, 1970

3) Fisher CM, Kistler JP, David JM: Relation of cerebral vasospasm to subarachnoid hemorrhage visualized by computerized tomographic scanning. Neurosurgery 6: 1-9, 1980

4) Gordon JL: Mechanism of platelet-collagen interaction. Nature 278: 13-14, 1979

5) Haining JL, Clower BR, Honama Y, Smith RR: Accumulation of intimal platelets in cerebral arteries following experimental subarachnoid hemorrhage in cats. Stroke 19: 898-902, 1988

6) Heros RC, Zervas NT, Varsos V: Cerebral vasospasm after subarachnoid hemorrhage: An update. Ann Neurol 14: 599-608, 1983

7) Hunt WE, Kosnik EJ: Timing and perioperative care in intracranial aneurysm surgery. Clin Neurosurg 21: $79-89,1974$

8) Hynes RO: Cell surface proteins and malignant transformation. Biochim Biophys Acta 458: 73-107, 1976

9) Jennett B, Bond M: Assessment of outcome after severe brain damage. Lancet 1: 480-491, 1975

10) Jilek $F$, Hörmann $\mathrm{H}$ : Cold-insoluble globulin: Plasminolysis of cold-insoluble globulin. Hoppe Seylers Z Physiol Chem 358: 133-136, 1977

11) Jilek F, Hörmann H: Cold-insoluble globulin (fibronectin): Affinity to soluble collagen of various types. Hoppe Seylers Z Physiol Chem 359: 247-250, 1978

12) Kassel NF, Sasaki T, Colohan ART, Mazar G: Cerebral vasospasm following aneurysmal subarachnoid hemorrhage. Stroke 16: 562-572, 1985 
13) Keiski-Oja J, Mosher DF, Vaheri A: Cross-linking of a major fibroblast surface-associated glycoprotein (fibronectin) catalyzed by blood coagulation factor XIII. Cell 9: 29-35, 1976

14) Mosher DF: Fibronectin. Prog Hemost Thromb 5: 111-151, 1980

15) Mosher DF, Schad PE, Vann JM: Cross-linking of collagen and fibronectin by factor XIIIa: Localization of participating glutaminyl residues to a tryptic fragment of fibronectin. $J$ Biol Chem 255: 11811188,1980

16) Mosher DF, Williams EM: Fibronectin concentration is decreased in plasma of severely ill patients with disseminated intravascular coagulation. $J$ Lab Clin Med 91: 729-735, 1978

17) Østergaard JR, Kristensen BØ, Svehag S-E, Teisner B, Miletic T: Immune complexes and complement activation following rupture of intracranial saccular aneurysms. $J$ Neurosurg 66: 891-897, 1987

18) Plow EF, Birdwell C, Ginsberg MH: Identification and quantification of platelet-associated fibronectin antigen. I Clin Invest 63: 540-543, 1979

19) Ruoslahti E, Vaheri A: Interaction of soluble fibroblast surface antigen with fibrinogen and fibrin: Identity with cold insoluble globulin of human plasma. J Exp Med 141: 497-501, 1975

20) Saba TM: Physiology and physiopathology of the reticuloendothelial system. Arch Intern Med 126: 1031-1052, 1970

21) Saba TM, Blumernstock FA, Scovill WA, Bernald $\mathrm{H}$ : Cryoprecipitate reversal of opsonic $\alpha 2$ surface binding glycoprotein deficiency in septic surgical and trauma patients. Science 201: 622-624, 1978

22) Saba TM, Jaffe E: Plasma fibronectin (opsonic glycoprotein): Its synthesis by vascular endothelial cells and role in cardiopulmonary integrity after trauma as related to reticuloendothelial function. $\mathrm{Am}$ $J$ Med 68: 577-594, 1980

23) Scovill WA, Saba TM, Kaplan JE, Bernard H, Poweres SR: Deficits in reticuloendothelial humoral control mechanisms in patients after trauma. $J$ Trauma 16: 898-904, 1976

24) Sherman LA, Harwig S, Lee J: In vitro formation and in vivo clearance of fibrinogen fibrin complexes. $J$ Lab Clin Med 86: 100-111, 1975

25) Stahkis NE, Mosesson MW, Chen AB, Galanakis DK: Cryoprecipitation of fibrin-fibrinogen complexes induced by the cold-insoluble globulin of plasma. Blood 51: 1211-1222, 1978

26) Suzuki $S$, Kimura $M$, Souma $M$, Ohkima $H$, Shimizu $\mathrm{T}$, Iwabuchi $\mathrm{T}$ : Cerebral microthrombosis in symptomatic cerebral vasospasm. A quantitative histological study in autopsy cases. Neurol Med Chir (Tokyo) 30: 309-316, 1990

27) Uttley AHC, Buckell M: Biochemical changes after spontaneous subarachnoid hemorrhage. Part III. Coagulation and lysis with special reference to recurrent haemorrhage. J Neurol Neurosurg Psychiat 31: 621-627, 1968

28) Yamada KM, Olden K: Fibronectins: Adhesive glycoproteins of cell surface and blood. Nature 275: 179-184, 1978

Address reprint requests to: S. Kashiwagi, M.D., Department of Neurosurgery, Yamaguchi University School of Medicine, 1144 Kogushi, Ube, Yamaguchi 755, Japan. 